\title{
PCAT6 may be a new prognostic biomarker in various cancers: a meta-analysis and bioinformatics analysis
}

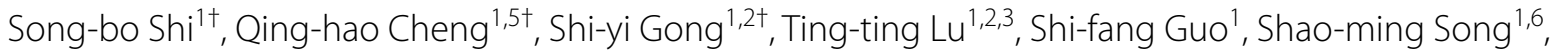
Yu-ping Yang ${ }^{1}$, Qi Cui ${ }^{1,5}$, Ke-hu Yang ${ }^{2,3,4^{*}}$ and Yao-wen Qian ${ }^{1 *}$ (D)

\begin{abstract}
Background: LncRNA prostate cancer-associated transcript 6 (PCAT6) has been reported to be dysregulated in several cancers and is associated with tumor progression. Here, we have performed a meta-analysis to assess the general prognostic role of PCAT6 in malignancies.

Methods: Four public databases (Embase, Pubmed, Web of Science, Cochrane Library) were used to identify eligible studies, then data was extracted and associations between prognostic indicators and clinical characteristics were combined to estimate hazard ratio (HR) or odds ratio (OR) with a 95\% confidence interval (Cl). Publication bias was measured using the Begg's test, and the stability of the combined results was measured using sensitivity analysis. Subsequently, results were validated using Gene Expression Profiling Interactive Analysis (GEPIA) and the National Genomics Data Center (NGDC).

Results: Ten studies were considered eligible for inclusion. In total, 937 patients and eight types of cancer were included. Our results revealed that overexpression of PCAT6 was significantly associated with a shorter OS (HR $=1.82$; $95 \% \mathrm{Cl},[1.40,2.38] ; P<0.0001)$ and progression-free survival (PFS) $(H R=1.66 ; 95 \% \mathrm{Cl},[1.22,2.25] ; P<0.0001)$ in cancer patients, and that PCAT6 overexpression was significantly associated with individual tumor clinicopathological parameters, including TNM stage $(\mathrm{OR}=0.29 ; 95 \% \mathrm{Cl},[0.09,0.94] ; P=0.04)$, gender $(\mathrm{OR}=1.84 ; 95 \% \mathrm{Cl},[1.31,2.59] ; P=0.0005)$, and whether the tumor was metastatic $(\mathrm{OR}=5.02 ; 95 \% \mathrm{Cl},[1.36,18.57] ; P=0.02)$. However, PCAT6 overexpression was not correlated with patient age and tumor differentiation. PCAT6 expression was significantly up-regulated in four types of cancer, which was validated using the GEPIA cohort. Combining OS and disease-free survival (DFS) of these four types of cancer revealed a shorter OS and DFS in patients with PCAT6 overexpression. PCAT6 expression in various types of cancer was also validated in NGDC. A total of eight cancers were analyzed and PCAT6 was highly expressed in all eight cancers. Further functional predictions suggest that PCAT6 is correlated with tumor prognosis, and that PCAT6 may be useful as a new tumor-specific marker.
\end{abstract}

\footnotetext{
*Correspondence: kehuyangebm2020@163.com; 3416556185@qq.com

†Song-bo Shi, Qing-hao Cheng and Shi-yi Gong contributed equally to this work

${ }^{1}$ Gansu Provincial Hospital, 204 Dong gang West Road, Cheng guan

District, Lanzhou, China

${ }^{3}$ Evidence-Based Medicine Center, School of Basic Medical Sciences,

Lanzhou University, No. 222, Tian shui South Road, Cheng guan District,

Lanzhou 730000, China

Full list of author information is available at the end of the article
}

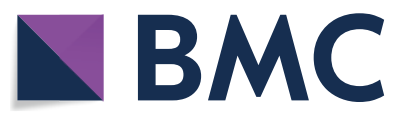

(c) The Author(s) 2021. This article is licensed under a Creative Commons Attribution 4.0 International License, which permits use, sharing, adaptation, distribution and reproduction in any medium or format, as long as you give appropriate credit to the original author(s) and the source, provide a link to the Creative Commons licence, and indicate if changes were made. The images or other third party material in this article are included in the article's Creative Commons licence, unless indicated otherwise in a credit line to the material. If material is not included in the article's Creative Commons licence and your intended use is not permitted by statutory regulation or exceeds the permitted use, you will need to obtain permission directly from the copyright holder. To view a copy of this licence, visit http://creativecommons.org/licenses/by/4.0/. The Creative Commons Public Domain Dedication waiver (http://creativecommons.org/publicdomain/zero/1.0/) applies to the data made available in this article, unless otherwise stated in a credit line to the data. 
Conclusions: LncRNA PCAT6 is highly expressed in multiple cancer types and its upregulation was significantly associated with patient prognosis and poorer clinical features, thereby suggesting that PCAT6 may be a novel prognostic factor in multiple cancer types.

Keywords: Cancers, IncRNA PCAT6, Meta-analysis, Prognosis

\section{Introduction}

Cancer is ranked globally as a leading cause of death and a significant barrier to increasing life expectancy. In 2020, there were an estimated 19.3 million new cancer cases and 10 million cancer deaths worldwide, and the incidence is expected to increase to a projected 28.4 million new cases by 2040 [1]. The American Cancer Society estimated that there will 1,806,590 new cancer cases in the United States in 2020, resulting in an estimated 606,520 cancer-related deaths [2]. In China, an estimated 4.51 million cancer cases and 3.04 million cancer-related deaths were reported in 2020 [3]. Despite rapid developments in medical technology and the increasing number and sophistication of treatment methods for tumors, the overall prognosis of cancer remains poor. One of the main reasons for this poor overall prognosis is the lack of specific markers for tumor diagnosis; thus, when a patient is diagnosed with cancer, it has usually progressed to the middle and late stages [4]. As a consequence of this delay in diagnosis, the optimal opportunity to treat cancer is usually lost. Hence, the search for specific tumor markers is of great importance in cancer diagnosis. Biological markers ('Biomarkers') play an increasingly important role in determining risk and detecting existing early-stage cancers or precancerous lesions [5]. These biomarkers can be biological indicators of normal biological processes, pathogenic processes, or pharmacological responses to therapeutic interventions.

Long non-coding RNAs (lncRNAs) are mRNA-like transcripts ranging in length from 200 nucleotides (nt) to 100 kilobases $(\mathrm{kb})$ with no apparent open reading frame (ORF) [6, 7]. Although initially considered as transcriptional noise, studies have revealed that IncRNAs are involved in a variety of pathophysiological processes, especially cancer, and an increasing number of lncRNAs are often aberrantly expressed in cancer [8-10]. Therefore, lncRNAs may be useful as biomarkers for early tumor detection and prognostic monitoring. In recent decades, research on lncRNAs has focused on the dysregulation of lncRNAs involved in the pathophysiological processes of human diseases, including cancer [11]. It is now known that lncRNAs play a role in a variety of biological processes, including autophagy, myocardial infarction, cellular senescence, apoptosis, cancer cell metastasis, and resistance to chemotherapeutic agents. In addition, they can modulate the regulation of gene expression through a variety of mechanisms, including epigenetic modification, selective splicing, nuclear import, precursors to small RNAs, and even as regulators of mRNA modifiers or decoy elements [12-16].

The discovery of lncRNAs has enriched our understanding of the diversity and complexity of genetic information. From a mechanistic perspective, studying lncRNAs is crucial for the development of new biomarkers and effective therapeutic targets for cancer patients. Our understanding of the role of lncRNAs in the progression and suppression of multiple tumors has resulted in novel opportunities to improve the diagnosis and treatment of malignancies [17, 18]. Meta-analyses revealed that HOXD-AS1[4], PODXL [19], and TP73AS1 [20] were associated with the clinicopathological characteristics and prognosis of tumors. LncRNA prostate cancer-associated transcript 6 (PCAT6), which was first identified in keratinocytes, indirectly activates the Wnt/ $\beta$-catenin pathway by interacting with KLHL12 in cervical cancer cells [21]. Using LncRNA microarrays, PCAT6 was further confirmed to be the most upregulated lncRNA expressed in cancer tissues, and it was revealed to be significantly associated with prostate cancer metastasis, induced-colony formation, and the proliferation of keratin-forming cells in prostate cells [22]. In addition, PCAT6 has been shown to be aberrantly expressed in osteosarcoma [23], ovarian [24], lung [25], colorectal [21], cervical [26], and pancreatic ductal cancers [27], thereby suggesting that PCAT6 is associated with the clinicopathological characteristics and prognosis of tumors.

Numerous studies have reported that aberrant expression of PCAT6 in various types of cancer correlates with pathological features, such as tumor size, metastasis, degree of differentiation, TNM stage, and prognosis [24-26]. To provide better clinical guidance to clinicians, in the present study we have performed a meta-analysis of the existing literature to investigate the relationship between PCAT6 and clinicopathological features and patient prognosis [28].

\section{Materials and methods}

\section{Search strategy}

This meta-analysis was conducted and reported according to the Preferred Reporting Items for Systematic Reviews and Meta-Analysis (PRISMA) guidance. Four 
databases, Embase, Pubmed, Web of Science, and Cochrane Library, were searched from database creation to 1st March 2021 with no language restrictions. For this search, Medical Subject Headings (MESH) terms and free terms were combined. Our search terms were: ("Neoplasms" OR "Carcinoma" OR "Prognosis" OR "Diagnosis" OR "Survival") AND ("Prostate cancer-associated ncRNA transcript 6" OR "PCAT6"). Two reviewers independently reviewed the database search strategies and discussed the results to ensure accuracy and consistency [29].

\section{Inclusion and exclusion criteria}

The inclusion criteria were as follows: (1) PCAT6 expression in cancer patients was examined in tumor tissues by qRT-PCR or RNA-seq; (2) patients had a clear diagnosis of cancer and the relationship between PCAT6 and survival information or clinicopathology was described; and (3) hazard ratio (HR) for overall survival (OS) and progression-free survival (PFS) were provided or could be calculated from survival curves.

The exclusion criteria were as follows: (1) reviews, case reports, letters, editorials, conference reports, and in vitro or in vivo experiments; and (2) it was not possible to extract the data or to perform valid operations on the extracted data.

\section{Literature selection and data extraction}

Two researchers (Cheng and Shi) independently searched and selected the literature based on the above-mentined criteria and extracted the following information: (1) name of first author; (2) publication year; (3) country where the study was performed; (4) types of cancer; (5) number of patients; (6) detection methods; (7) cut-off criteria; (8) clinical parameters; (9) OS data; and (10) PFS data.

\section{Data extraction and quality assessment}

Two reviewers (Cheng and Shi) independently extracted the data and assessed the quality of included studies. Disagreements were resolved by consultations with the third reviewer [30]. The quality of the studies was assessed using the Newcastle-Ottawa scale (NOS). The assessment scale consisted of three domains: selection of study groups; comparability; exposure (case-control study); or outcome (cohort study). The maximum total score was nine points; one star represented one point. The scores were divided into low quality (0-3), medium quality (4-6), and high quality (7-9), which was based on the total score.

\section{Public data and tools}

Gene Expression Profiling Interactive Analysis (GEPIA; http://gepia.cancer-pku.cn), which is based on The Cancer Genome Atlas (TCGA; http://cancergenome.nih. gov/) [31], was performed to verify the abnormal expression of PCAT6 among cancer tissues and to match TCGA normal and GTEx data among various neoplasms (cutoff, $P<0.01)$. Survival plots of the correlation between PCAT6 expression and OS and disease-free survival (DFS) were retrieved as Kaplan-Meier curves based on different cancer datasets. To further validate our results, PCAT6 expression in various cancer types was retrieved from the Database Resources of the National Genomics Data Center (NGDC; https://bigd.big.ac.cn) [32].

\section{Statistical analysis}

RevMan (Version 5.4) software was used to calculate the pooled ORs and HR with $95 \%$ CIs. The $I^{2}$ value and the $X^{2}$-test were used to assess heterogeneity. A fixed-effects model was used if the heterogeneity was low $\left(P>0.1, I^{2}\right.$ $\leq 50 \%$ ), and a random effect model was used if the heterogeneity was high $\left(P<0.1, I^{2}>50 \%\right.$.). A $P<0.05$ was considered statistically significant. Engauge Digitizer (Version 10.0) software was used to extract survival data from the Kaplan-Meier curves. Begg's tests and sensitivity analyses were performed using Stata SE12.0 software. Begg's tests were used to assess potential publication bias, while sensitivity analyses were used to examine sources of heterogeneity and the stability of the results.

\section{Results}

\section{Literature screening}

We searched four databases to retrieve a total of 92 studies (Pubmed $=30$, Cochrane Library $=0$, Web of Science $=30$, Embase $=32$ ). A total of 58 duplicate articles were removed using Endnote X9. After further examination of the titles and abstracts, 10 irrelevant studies were excluded. Finally, the full text of 24 articles was carefully examined. One article was excluded because data could not be extracted, seven articles were excluded because patient information was missing, and five articles were excluded because the experiments were performed on cells only. Finally, a total of 10 articles [17, 21, 23-27, 3335 ] were included in this study. Information concerning the selection process is provided in Fig. 1.

\section{Study characteristics and quality assessment}

The characteristics of the 10 included studies are listed in Table 1. One study [34] had a score of seven and was considered of high quality, eight studies [17, 21, 23-27, 33] had a score of six, and one study [35] had a score of five, and were considered of moderate quality. These studies were published in 2017-2020 with sample sizes ranging from 43 to 114 . In all ten studies, 937 patients were divided into PCAT6 high and low expression groups based on the results obtained by RT-qPCR. The types of cancer included osteosarcoma, cervical cancer, lung 

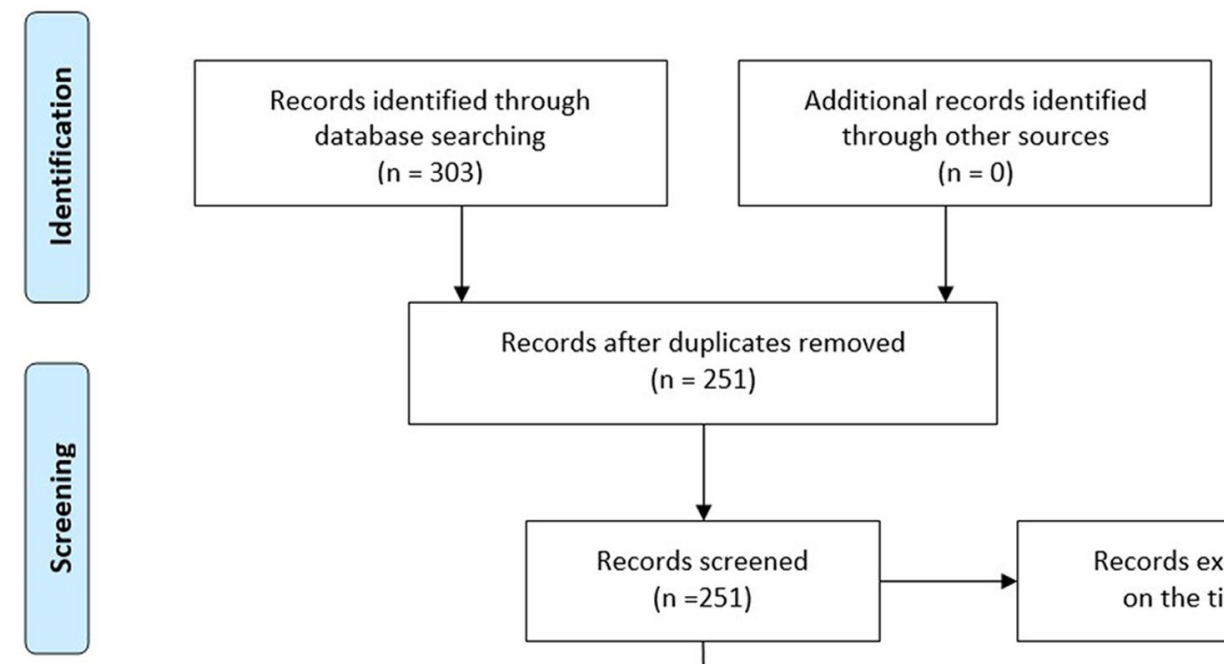

Records after duplicates removed $(\mathrm{n}=251)$
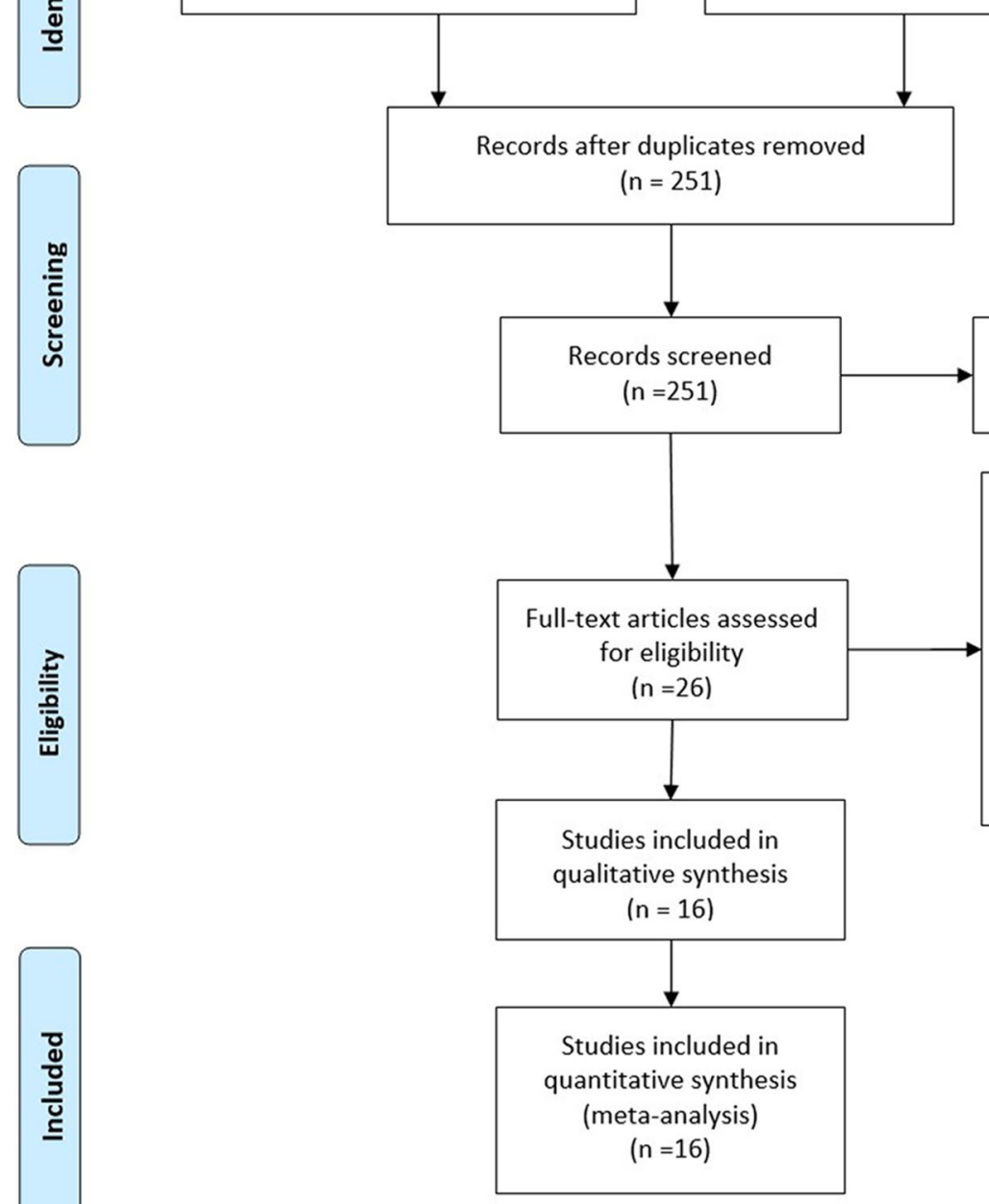

Records excluded $(\mathrm{n}=225)$ on the titles/abstracts

Full-text articles excluded, with reasons $(n=10)$

1. Non-human studies

$$
(n=4)
$$

2. Physical experimental studies

$$
(n=5)
$$

3. Unable to extract data

$$
(n=1)
$$

Fig. 1 Flow chart of the literature search and selection process

cancer, pancreatic ductal adenocarcinoma, colorectal cancer, bladder cancer, gastric cancer, and ovarian cancer. In total, eight studies reported OS results, four studies reported PFS results, and all 10 included studies reported results for clinicopathological parameters.

\section{Meta-analysis}

\section{Association between PCAT6 expression and prognosis}

For the eight studies [17, 21, 23, 26, 27, 33-35] that reported OS, a total of 656 patients were included. Since no statistical heterogeneity was observed between these studies $\left(P=1.00, I^{2}=0 \%\right)$, a fixed-effects model was used for statistical analysis. The results revealed a significant correlation between high PCAT6 expression and a lower OS (HR $=1.82$, 95\% CI: [1.40, 2.38], $P<0.0001$, Fig. 2A).

For the eight studies [23, 26, 34, 35] that reported the DFS of patients, no statistical heterogeneity was observed between studies $\left(P=0.68, I^{2}=0 \%\right)$, and a fixed-effect model was used for statistical analysis. The results revealed a significant correlation between high PCAT6 expression and a lower PFS $(\mathrm{HR}=1.66 ; 95 \% \mathrm{CI},[1.22,2.25] ; P<0.0001$; Fig. 2B). 
Table 1 Characteristics of eligible studies in this meta-analysis

\begin{tabular}{|c|c|c|c|c|c|c|c|c|c|}
\hline ID & Year & Country & Sample size (high/low) & Cancer type & Method & Outcomes & HR availability & $\begin{array}{l}\text { Follow-up } \\
\text { months } \\
\text { (mouth) }\end{array}$ & NOS Score \\
\hline Zhu 2020 [35] & 2020 & China & $60(30 / 30)$ & Osteosarcoma & qRT-PCR & OS, PFS, CP & K-M curve & 60 & 5 \\
\hline Lv 2019 [27] & 2019 & China & $114(58 / 56)$ & Cervical cancer & qRT-PCR & OS, PFS, CP & K-M curve & 60 & 6 \\
\hline Wan 2016 [18] & 2016 & China & $58(27 / 31)$ & Lung cancer & qRT-PCR & $\mathrm{OS}, \mathrm{CP}$ & K-M curve & 60 & 6 \\
\hline Wang 2020 [28] & 2020 & China & $67(37 / 30)$ & $\begin{array}{l}\text { Pancreatic ductal } \\
\text { adenocarci- } \\
\text { noma }\end{array}$ & qRT-PCR & $\mathrm{OS}, \mathrm{CP}$ & K-M curve & 60 & 6 \\
\hline Wu 2019 [26] & 2019 & China & $73(37 / 36)$ & Colorectal cancer & qRT-PCR & $\mathrm{OS}, \mathrm{CP}$ & K-M curve & 60 & 6 \\
\hline Wu 2020 [23] & 2020 & China & $106(70 / 36)$ & Osteosarcoma & qRT-PCR & OS, PFS, CP & K-M curve & 60 & 6 \\
\hline Zhang 2020 [34] & 2020 & China & $106(53 / 53)$ & Bladder cancer & qRT-PCR & OS, PFS, CP & K-M curve & 150 & 7 \\
\hline Xu 2018 [33] & 2018 & China & $72(36 / 36)$ & Gastric cancer & qRT-PCR & $\mathrm{OS}, \mathrm{CP}$ & K-M curve & 100 & 6 \\
\hline Shi 2018 [25] & 2018 & China & $60(31 / 29)$ & Lung cancer & qRT-PCR & $\mathrm{CP}$ & K-M curve & - & 6 \\
\hline Kong 2019 [24] & 2019 & China & $42(18 / 24)$ & Ovarian cancer & qRT-PCR & $\mathrm{CP}$ & K-M curve & - & 6 \\
\hline
\end{tabular}

OS overall survival, PFS progression-free survival, CP clinicopathological parameters, NOS Newcastle-Ottawa Scale, K-M curve Kaplan-Meier curve, $q R T-P C R$ quantitative real time polymerase chain reaction, -, not available or invalid

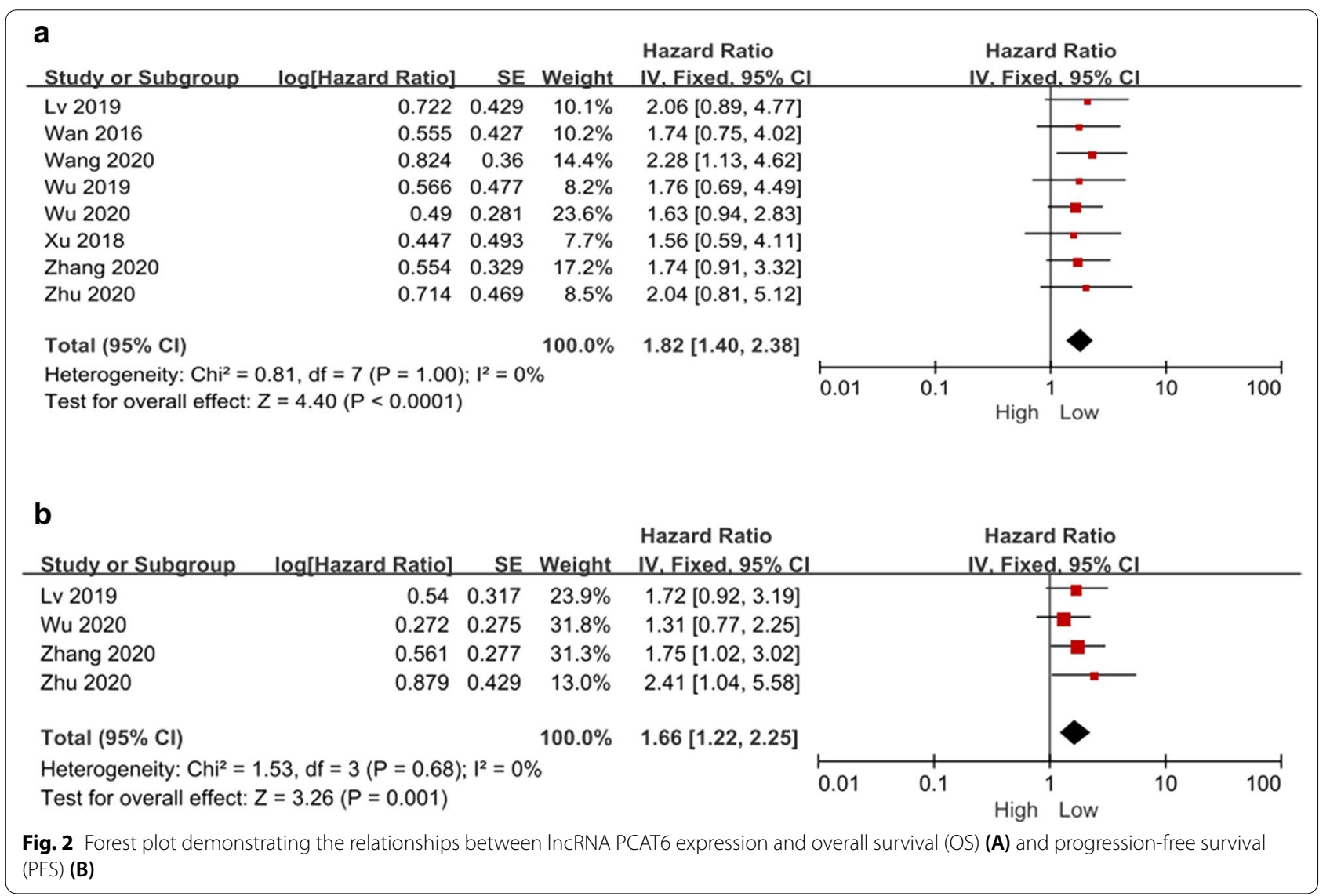

\section{Relationship between PCAT6 expression} and clinicopathological parameters

All 10 included studies reported clinicopathological parameters of PCAT6 overexpression. These results are shown in Table 2. Nine studies [17, 21, 23-27, $33,34]$ reported the relationship between PCAT6 overexpression and age, but no significant correlation was observed $(\mathrm{OR}=0.80 ; 95 \% \mathrm{CI},[0.51,1.23]$; 
Table 2 Meta-analysis of the studies reporting the association between over-expressed PCAT6 and clinicopathological parameters

\begin{tabular}{|c|c|c|c|c|c|c|c|}
\hline \multirow[t]{2}{*}{ Clinicopathological parameters } & \multirow[t]{2}{*}{ Studies } & \multirow[t]{2}{*}{ Patients } & \multirow[t]{2}{*}{ Mode } & \multirow[t]{2}{*}{ OR $(95 \% \mathrm{Cl})$} & \multirow[t]{2}{*}{$P$ value } & \multicolumn{2}{|c|}{ Heterogeneity } \\
\hline & & & & & & $I^{2}(\%)$ & P-value \\
\hline Age (old vs young) & 9 & 736 & Random & $0.80[0.51,1.23]$ & 0.31 & 53 & 0.03 \\
\hline Gender (male vs female) & 7 & 267 & Fixed & $1.84[1.31,2.59]$ & 0.0005 & 0 & 0.60 \\
\hline Tumor size (big vs small) & 6 & 524 & Random & $2.73[1.00,7.44]$ & 0.05 & 86 & $<0.00001$ \\
\hline TNM stage (I + II VS III + IV) & 6 & 211 & Random & $0.29[0.09,0.94]$ & 0.04 & 86 & $<0.00001$ \\
\hline Differentiation (well + moderat vs poor) & 4 & 306 & Random & $1.77[0.21,15.11]$ & 0.60 & 94 & $<0.00001$ \\
\hline Metastasis (yse vs no) & 10 & 746 & Random & $5.02[1.36,18.57]$ & 0.02 & 93 & $<0.00001$ \\
\hline
\end{tabular}

Random Random-effects, Fixed Fixed-effects, OR Odds ratio, $\mathrm{Cl}$ confidence interval

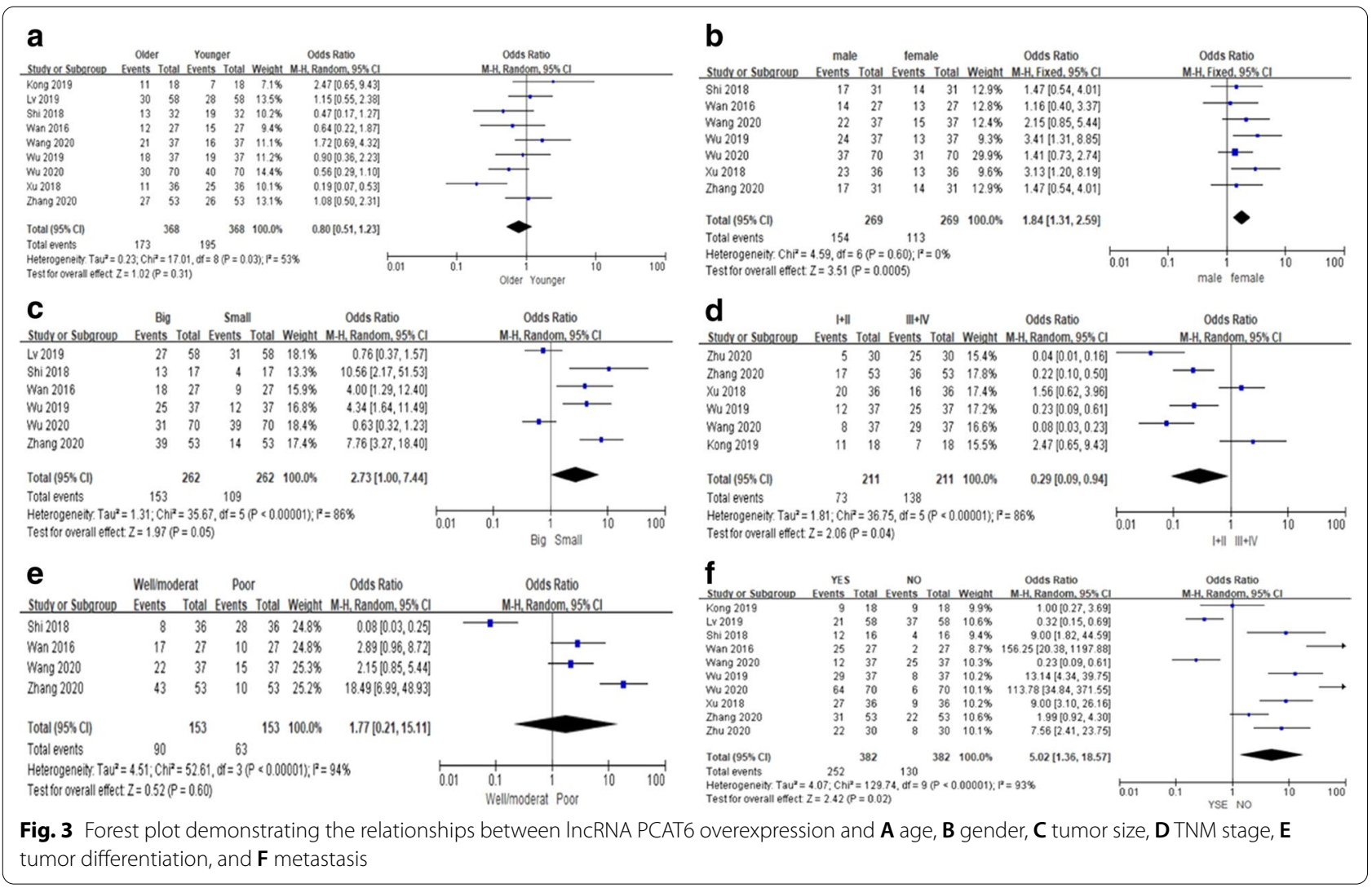

$P=0.31$; Fig. 3A). Seven studies $[17,21,23,25,27,33$, 34] reported the relationship between PCAT6 overexpression and gender, and a significant correlation was observed between male sex and PCAT6 overexpression $(\mathrm{OR}=1.84 ;$; 95\% CI, [1.31, 2.59]; $P=0.0005$, Fig. 3B). Six studies $[17,21,23,25,26,34]$ reported the correlation between PCAT6 overexpression and tumor size. Although a correlation was observed between PCAT6 overexpression and a larger tumor size, the results were not statistically significant $(\mathrm{OR}=2.73$; 95\% CI, [1.00, 7.44]; $P=0.05$; Fig. 3C). Six studies
[21, 24, 27, 33-35] reported the relationship between PCAT6 overexpression and TNM stage. A significant correlation was observed between PCAT6 overexpression and TNM stage, and there was a significant correlation between PCAT6 overexpression and clinically advanced stage (III/IV) $(\mathrm{OR}=0.29 ; 95 \% \mathrm{CI},[0.09$, 0.94]; $P=0.04$; Fig. 3D). Four studies $[17,25,27,34]$ reported a relationship between the degree of tumor differentiation and high PCAT6 expression, however, no significant correlation was observed $(\mathrm{OR}=1.77$; 95\% CI, [0.21, 15.11]; $P=0.60$; Fig. 3 E). All 10 studies 
reported a correlation between high PCAT6 expression and the presence of metastasis, and the combined results showed a significant correlation between high PCAT6 expression and metastasis $(\mathrm{OR}=5.02 ; 95 \% \mathrm{CI}$, $[1.36,18.57] ; P=0.02$; Fig. 3F).

\section{Subgroup analysis}

Because of the high heterogeneity in the results concerning clinicopathological parameters, subgroup analysis was performed to identify sources of heterogeneity basesd on the cancer type. Two studies [17, 25] reported correlations between high PCAT6 expression and tumor size, age, degree of differentiation, and metastasis in lung cancer. A significant correlation between high PCAT6 expression and larger lung tumors was observed $(\mathrm{OR}=5.57 ; 95 \% \mathrm{CI},[2.24,13.84] ; P=0.0002$; Fig. 4A), with no heterogeneity between studies $(P=0.33$, $\left.I^{2}=0 \%\right)$. No correlation was observed between high PCAT6 expression and the age of lung cancer patients $(\mathrm{OR}=0.54 ; 95 \% \mathrm{CI},[0.26,1.12] ; P=0.10$; Fig. $4 \mathrm{~B})$, with no heterogeneity between studies $\left(P=0.68 ; I^{2}=0 \%\right)$. Although a correlation between high PCAT6 expression and lower differentiation of lung cancer was observed $(\mathrm{OR}=0.49 ; 95 \% \mathrm{CI},[0.01,16.02] ; P=0.69$; Fig. $4 \mathrm{C})$, there was high heterogeneity between studies $(\mathrm{P}<0.00001$, $\left.\mathrm{I}^{2}=95 \%\right)$. Likewise, although a significant correlation between high PCAT6 expression and metastasis of lung cancer was observed (OR $=34.88$; 95\% CI, [2.13, 570.79]; $P=0.01$; Fig. $4 \mathrm{D})$, the data showed high heterogeneity $\left(P=0.03, I^{2}=79 \%\right)$. In addition, two studies $[23,35]$ reported a correlation between high PCAT6 expression and metastatic osteosarcoma. Although a significant correlation between high PCAT6 expression and metastatic osteosarcoma was observed $(\mathrm{OR}=29.21 ; 95 \% \mathrm{CI},[2.05$, 416.19]; $P=0.01$; Fig. $4 \mathrm{E}$ ), there was significant heterogeneity between studies $\left(P=0.001, I^{2}=90 \%\right)$.

\section{Sensitivity analysis}

To assess the stability of the combined results, we performed a sensitivity analysis of the correlation between PCAT6 expression and OS. The sensitivity analysis showed that no individual study changed the combined results, and therefore, the OS results were considered reliable (Fig. 5F). Sensitivity analysis was also performed on the clinicopathological parameters results (Fig. 5AE). Sensitivity analysis of the correlation between high PCAT6 expression and age showed a significant reduction in heterogeneity after excluding the studies of Kong et al. [24] and Xu et al. [33] $\left(P=0.38, I^{2}=6 \%\right)$, however, no significant effect was observed on the final results $(\mathrm{OR}=0.86$; $95 \% \mathrm{CI},[0.63,1.17] ; P=0.34)$. In the sensitivity analysis on tumor size, it was found that excluding the studies of Lv et al. [26] and Wu et al. [23] completely eliminated heterogeneity $\left(P=0.63, I^{2}=0 \%\right)$, and there was a significant correlation between high PCAT6 expression and tumor size $(\mathrm{OR}=5.86$; 95\% CI, [3.46, 9.90]; $P<0.00001)$. Moreover, sensitivity analysis of the correlation between high PCAT6 expression and TNM staging suggested that the study by $\mathrm{Xu}$ et al. [33] may be the source of heterogeneity. However, exclusion of this study did not completely eliminate heterogeneity, suggesting more robust results. Among the outcome indicators regarding the degree of tumor differentiation, studies performed by Shi et al. [25] and Zhang et al. [34] were found to be sources of heterogeneity, and after excluding these two studies, heterogeneity was eliminated $\left(P=0.69, I^{2}=0 \%\right)$, thereby revealing a significant correlation between better differentiation and high expression of PCAT6 (OR $=2.43$; 95\% CI, $[1.20,4.94] ; P=0.01)$. During the sensitivity analysis of the correlation between high PCAT6 expression and tumor metastasisis, the study by Wan et al. [17] was identified as a source of heterogeneity. However, exclusion of this study did not eliminate heterogeneity and had no significant effect on the final results, suggesting more robust results.

\section{Analysis of publication bias}

The publication bias for PCAT6 expression and OS was analyzed using a Begg's funnel plot (Fig. 6). No obvious publication bias was observed in the included studies. Begg's test results $(\operatorname{Pr}>|z|=0.902)$ revealed no publication bias.

\section{Validation of PCAT6 expression in public databases}

To further validate our results, PCAT6 expression was evaluated in nine cancers using GEPIA clinical data. The results revealed that PCAT6 was up-regulated in most cancers, including Cholangio carcinoma $(\mathrm{CHOL})$, lung squamous cell carcinoma (LUSC), ovarian serous cystadenocarcinoma (OV), and thymoma (THYM) (Fig. 7). Furthermore, high expression of PCAT6 indicated poor patient prognosis. The prognostic data for four cancers (CHOL, LUSC, OV, and THYM) were combined. Next, 1062 patients with nine cancer types were divided into two groups based on median levels of PCAT6 expression. OS and DFS were shorter in the PCAT6 high expression group compared to the PCAT6 low expression group, thereby confirming that PCAT6 overexpression was associated with poor OS in various human cancers $(P<0.0001)$ (Fig. 8). These results are similar to the results obtained in our present study.

We also used NGDC to search and validate the expression of PCAT6 in various cancers. Finally, we validated PCAT6 expression in various cancers in lnCAR, an online analysis site based on Gene Expression Omnibus (GEO) [36]. A total of 30 datasets were collected, representing 


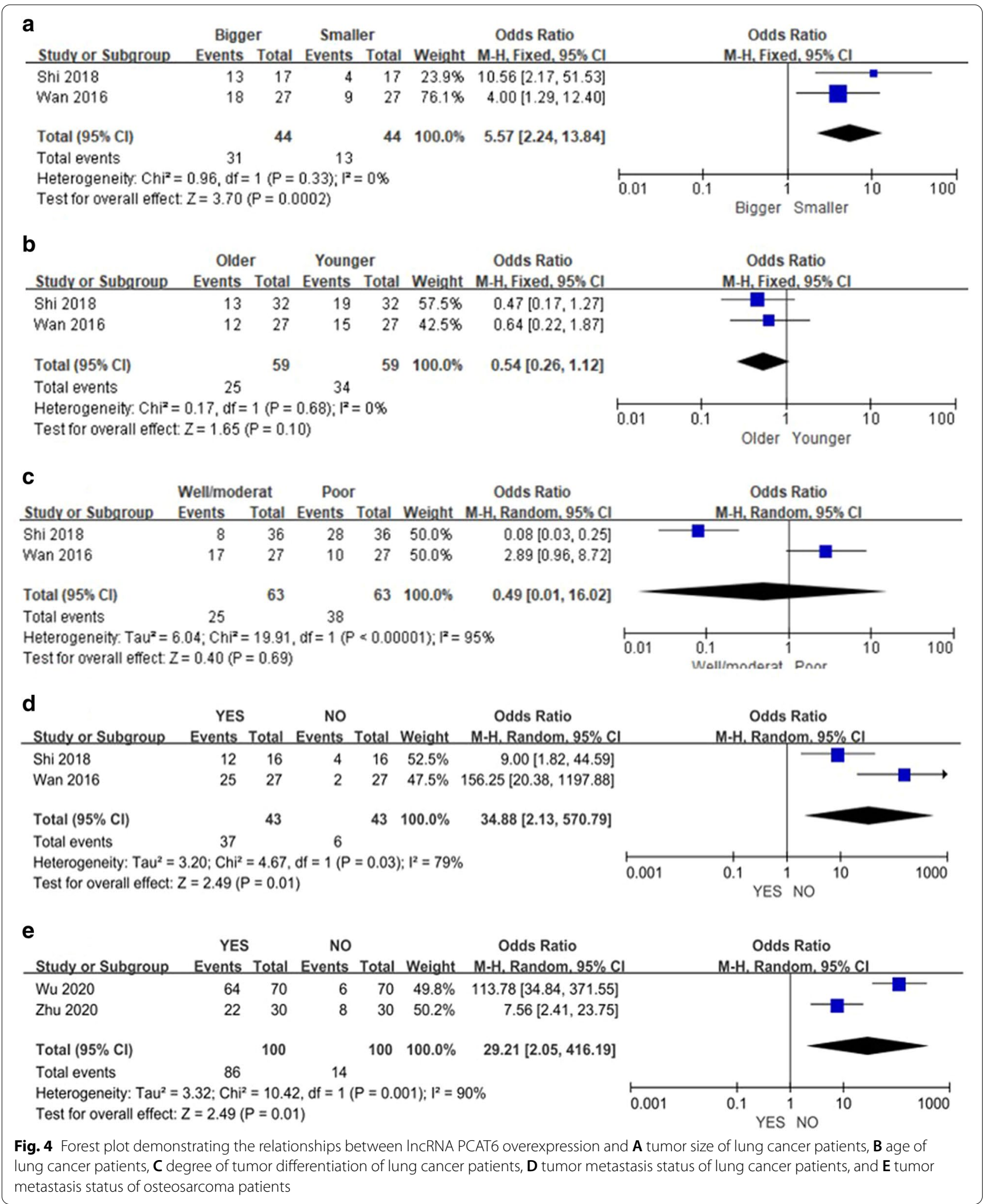



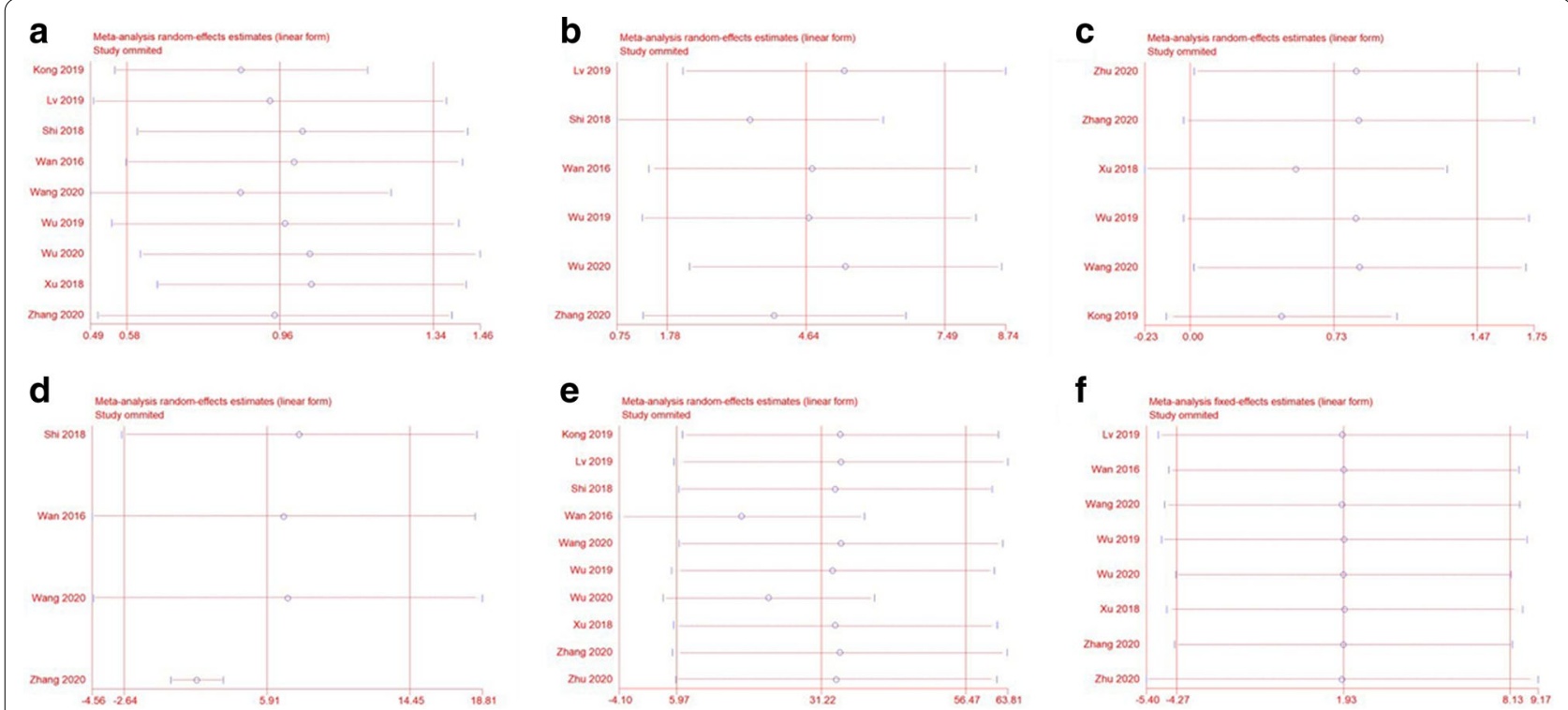

Fig. 5 Sensitivity analysis for the meta-analysis of the association between IncRNA PCAT6 overexpression and A age, B tumor size, C TNM stage, D tumor differentiation, and $\mathbf{E}$ metastasis. Sensitivity analysis for the meta-analysis of the association between IncRNA PCAT6 expression and overall survival (OS) (F)

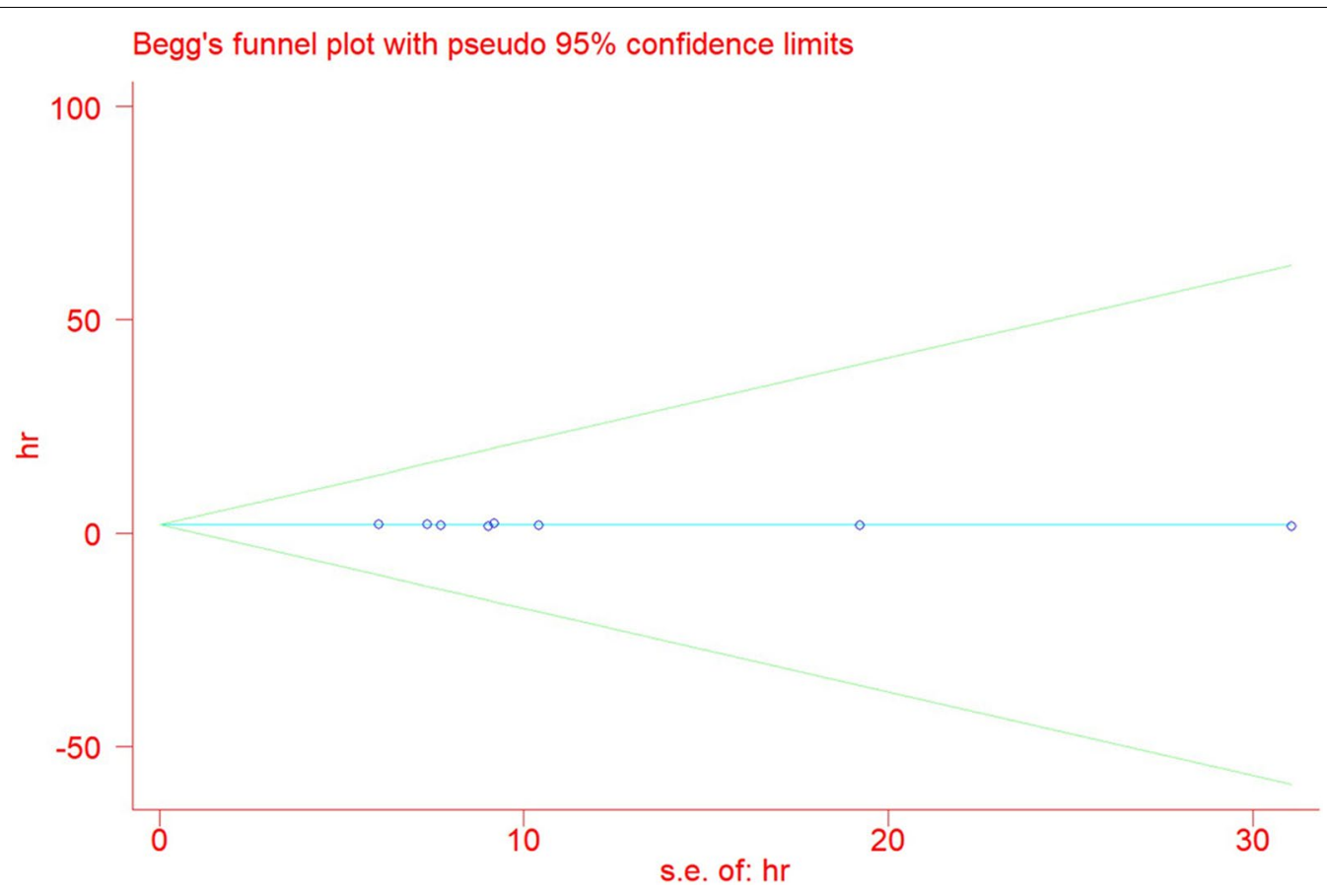

Fig. 6 Begg's publication bias plots of overall survival (OS)

data from a total of six types of cancer (bladder cancer, breast cancer, colorectal cancer, lung cancer, prostate cancer, and ovarian cancer). In comparison with normal tissue, PCAT6 expression was increased in all included cancer tissues, and the observed differences were statistically significant $(P<0.05)$. The results are shown in Table 3. 

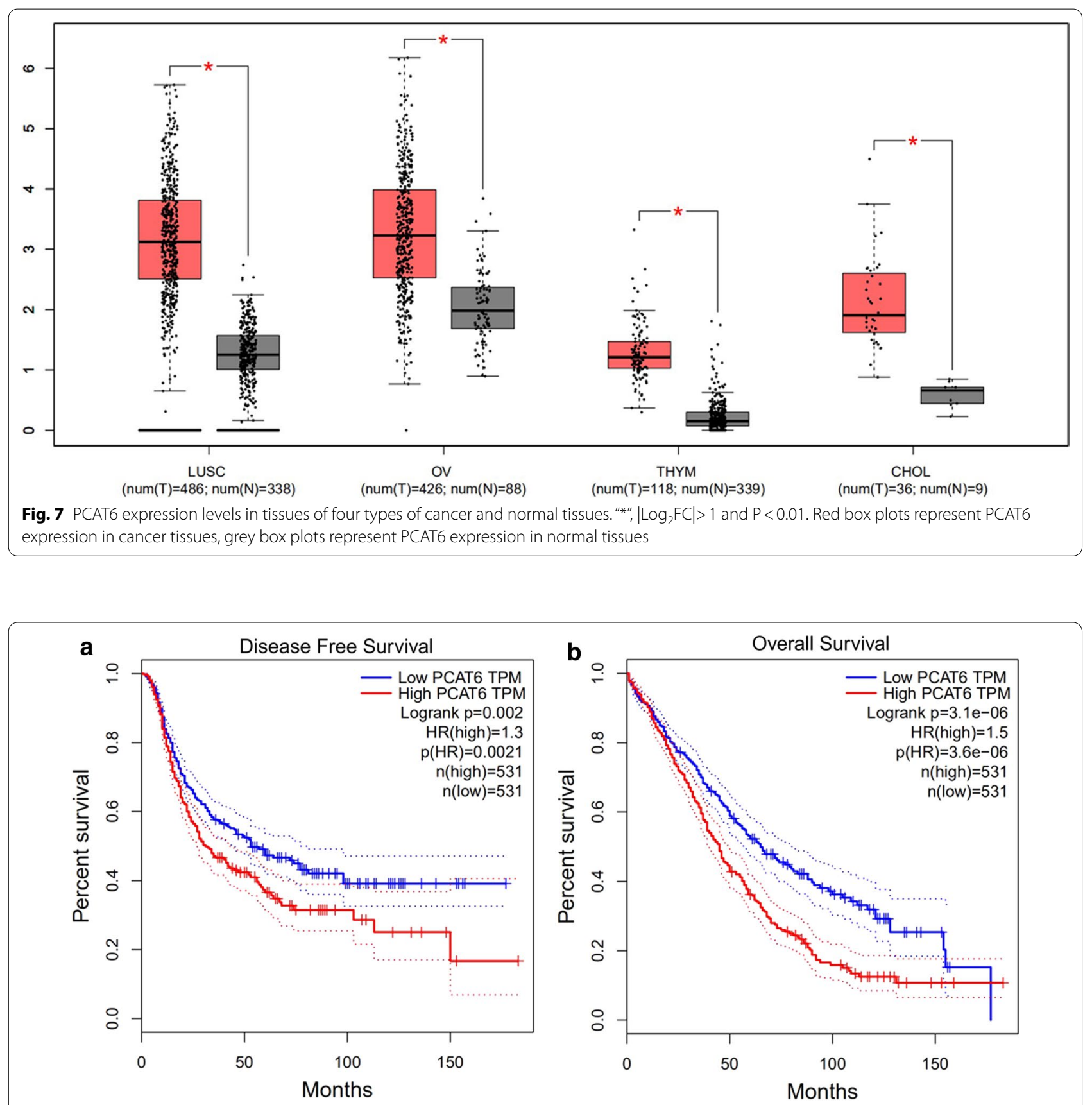

Fig. 8 The relationship between PCAT6 expression and cancer patient prognosis in the GEPIA cohort. A Overall survival (OS) plots based on PCAT6 expression in four types of cancer ( $\mathrm{n}(\mathrm{low})=531 \mathrm{vs} n$ (high) $=531$ ). B Disease-free survival (DFS) plots based on PCAT6 expression in four types of cancer $(\mathrm{n}($ low $)=531$ vs $\mathrm{n}($ high $)=531)$

\section{Molecular mechanisms of PCAT6 oncogenesis in various cancers}

The known molecular mechanisms of PCAT6 oncogenesis in various cancers are summarized below.

- In lung cancer, PCAT6 combined with EZH2 to reduce LATS2 promoter activity (via H3K27 tri- methylation in the LATS2 promoter region) and regulated miR-330-5p, thereby affecting proliferation and metastasis of non-small cell lung cancer (NSCLC) cells. In addition, PCAT6 affected the biological function of lung cancer cells by modulating the expression of two cancer-related proteins, c-Myc and p53 [17, 25, 37]. 
Table 3 Differential expression of PCAT6 in different cancers

\begin{tabular}{|c|c|c|c|c|c|}
\hline \multirow[t]{2}{*}{ Tumor Type } & \multirow[t]{2}{*}{ GSE number } & \multicolumn{2}{|c|}{ Sample Number } & \multirow[t]{2}{*}{ Expression } & \multirow[t]{2}{*}{ P-value } \\
\hline & & Tumor & Normal & & \\
\hline \multirow[t]{6}{*}{ Bladder cancer } & GSE13570 & 188 & 68 & High & 0.0000 \\
\hline & GSE89006 & 4 & 4 & High & 0.0271 \\
\hline & GSE7476 & 9 & 3 & High & 0.0068 \\
\hline & GSE37817 & 18 & 6 & High & 0.0057 \\
\hline & GSE52519 & 9 & 3 & High & 0.0323 \\
\hline & GSE76211 & 3 & 3 & High & 0.0892 \\
\hline \multirow[t]{4}{*}{ Breast cancer } & GSE42568 & 104 & 17 & High & 0.0004 \\
\hline & GSE45827 & 130 & 11 & High & 0.0007 \\
\hline & GSE50428 & 26 & 5 & High & 0.0000 \\
\hline & GSE65194 & 163 & 11 & High & 0.0016 \\
\hline \multirow[t]{4}{*}{ Breast cancer (Invasive ductal carcinoma) } & GSE10780 & 42 & 143 & High & 0.0000 \\
\hline & GSE10810 & 22 & 22 & High & 0.0004 \\
\hline & GSE21422 & 5 & 5 & High & 0.0003 \\
\hline & GSE40206 & 73 & 73 & High & 0.0000 \\
\hline Breast cancer (Inflammatory breast cancer) & GSE17907 & 21 & 4 & High & 0.0185 \\
\hline \multirow[t]{5}{*}{ Colorectal cancer } & GSE21510 & 123 & 25 & High & 0.0000 \\
\hline & GSE21815 & 132 & 9 & High & 0.0000 \\
\hline & GSE37364 & 27 & 38 & High & 0.0000 \\
\hline & GSE39582 & 566 & 19 & High & 0.0001 \\
\hline & GSE83889 & 101 & 35 & High & 0.0008 \\
\hline \multirow[t]{2}{*}{ Lung cancer } & GSE27262 & 25 & 25 & High & 0.0000 \\
\hline & GSE89039 & 8 & 8 & High & 0.0000 \\
\hline Lung cancer (Non-small cell) & GSE101929 & 32 & 34 & High & 0.0000 \\
\hline \multirow[t]{4}{*}{ Prostate cancer } & GSE8511 & 25 & 16 & High & 0.0004 \\
\hline & GSE32571 & 59 & 39 & High & 0.0002 \\
\hline & GSE38241 & 18 & 21 & High & 0.0000 \\
\hline & GSE68555 & 66 & 83 & High & 0.0000 \\
\hline \multirow[t]{3}{*}{ Ovarian cancer } & GSE18520 & 53 & 10 & High & 0.0003 \\
\hline & GSE40595 & 31 & 8 & High & 0.0001 \\
\hline & GSE54388 & 16 & 6 & High & 0.0047 \\
\hline
\end{tabular}

- In osteosarcoma, PCAT6 promoted the progression of osteosarcoma by sponging miR-185-5p to activate the TGF- $\beta$ pathway, by regulating the miR-143-3p/ ZEB1 pathway, and promoting the expression of MDM2, and by inhibiting the expression of p53 and p21 [35, 38].

- In bladder cancer, PCAT6 promoted the progression of bladder cancer cells by targeting miR-513a-5p [39].

- In breast cancer, PCAT6 promoted Triple-Negative Breast Cancer (TNBC) cell proliferation, migration, invasion, epithelial-mesenchymal transition (EMT), and angiogenesis, as well as tumor growth and metastasis, via upregulation of VEGFR2 by sponging miR-4723-5p and recruitment of USP14 [40].

- In gastric cancer, PCAT6 promoted the proliferation and metastasis of gastric cancer cells by endog- enously upregulating MKRN3 expression in competition with miR-30 [33].

- In ovarian cancer, PCAT6 promoted the development and progression of ovarian cancer by regulating PTEN. In vitro experiments also revealed that suppression of PTEN expression counteracted the role of PCAT6 in ovarian cell carcinoma [24].

- In cervical cancer, PCAT6 promoted the progression of cervical cancer by regulating the Wnt/ $\beta$-catenin pathway, secreting miR-543, and by upregulating ZEB1 [26, 41].

- In cholangiocarcinoma, PCAT6 induces cell proliferation and invasion by decreasing miR-330-5p expression in cholangiocarcinoma cells [42].

- In glioblastoma, PCAT6 upregulates IGF2BP1 expression via miR-513, forming a PCAT6/ miR-513/ 
IGF2BP1 positive feedback loop, and thus promoting glioblastoma progression [43].

- In pancreatic ductal carcinoma, PCAT6 promoted the growth of pancreatic ductal carcinoma by secreting miR-185-5p to upregulate the expression of the cancer-related gene CBX2 [27].

- In intestinal mesenchymal tumors, PCAT6 promoted proliferation of gastrointestinal mesenchymal tumor cells by upregulating PRDX5 via miR-143-3p [44].

- In pituitary adenomas, PCAT6 may promote pituitary adenoma progression in vitro and in vivo by targeting the miR-139-3p/ BRD4 axis [45].
The details of these molecular mechanisms are summarized in Table 4.

\section{Discussion}

With the rapid increase of cancer incidence and mortality worldwide, cancer is set to become the leading cause of death, and a significant impediment to increasing life expectancy in all countries this century [46]. In many cancers, over-activation or overexpression of anti-apoptotic proteins is frequently observed, and an imbalance between cell growth and apoptosis is an integral part of the oncogenic process of tumors, which makes tumor treatment challenging [47]. Although in recent decades cancer treatment has notably progressed, the prognosis

Table 4 Molecular mechanisms of PCAT6 oncogenesis in various cancers

\begin{tabular}{|c|c|c|c|}
\hline Tumor type & Expression & Molecular mechanisms & References \\
\hline Ovarian cancer & High & $\begin{array}{l}\text { Promotes ovarian carcinogenesis and progression by regulating PTEN, while } \\
\text { suppression of PTEN expression counteracts the role of PCAT6 in ovarian cell } \\
\text { carcinoma }\end{array}$ & {$[23]$} \\
\hline Cervical cancer & High & $\begin{array}{l}\text { Promotes proliferation and metastasis of cervical cancer cells through regulation of } \\
\text { the Wnt/ } \beta \text {-catenin pathway }\end{array}$ & {$[26]$} \\
\hline Colon cancer & High & $\begin{array}{l}\text { Promote apoptosis in colon cancer cells by regulating the level of anti-apoptotic } \\
\text { protein ARC }\end{array}$ & {$[46]$} \\
\hline \multirow[t]{3}{*}{ Lung cancer } & High & $\begin{array}{l}\text { Reduces LATS2 promoter activity by binding to EZH2 leading to } \mathrm{H} 3 \mathrm{~K} 27 \text { trimethyla- } \\
\text { tion in the LATS2 promoter region, thereby affecting the proliferation and metasta- } \\
\text { sis of non-small cell lung cancer cells }\end{array}$ & {$[25]$} \\
\hline & High & $\begin{array}{l}\text { Influences the biological function of lung cancer cells by affecting the expression of } \\
\text { p53 and c-Myc, key proteins that regulate cancer progression }\end{array}$ & {$[17]$} \\
\hline & High & $\begin{array}{l}\text { Promotes proliferation, migration, and invasion of non-small cell lung cancer cells } \\
\text { through regulation of miR-330-5p }\end{array}$ & {$[37]$} \\
\hline Pancreatic ductal carcinoma & High & $\begin{array}{l}\text { Promotes the proliferation, migration, and invasion of pancreatic ductal carcinoma } \\
\text { cells by secreting miR-185-5p to upregulate the expression of the cancer-related } \\
\text { gene CBX2 }\end{array}$ & {$[27]$} \\
\hline \multirow[t]{3}{*}{ Osteosarcoma } & High & $\begin{array}{l}\text { Progression of osteosarcoma is accelerated by regulating the miR-143-3p/ ZEB1 } \\
\text { pathway }\end{array}$ & {$[23]$} \\
\hline & High & $\begin{array}{l}\text { Activation of TGF- } \beta \text { pathway promotes osteosarcoma progression by sponging miR- } \\
185-5 p \text { and upregulating the expression of TGFBR1 and TGFBR2 }\end{array}$ & {$[35]$} \\
\hline & High & $\begin{array}{l}\text { Promotes proliferation, migration, and invasion of osteosarcoma cells by suppressing } \\
\text { p53 and p21 expression through promotion of MDM2 expression }\end{array}$ & {$[33]$} \\
\hline Stomach cancer & High & $\begin{array}{l}\text { Promotes proliferation and metastasis of gastric cancer cells by endogenously com- } \\
\text { peting with miR-30 to upregulate MKRN3 expression }\end{array}$ & [39] \\
\hline Bladder cancer & High & Promotes the progression of bladder cancer cells by targeting miR-513a-5p & {$[43]$} \\
\hline Glioblastoma & High & $\begin{array}{l}\text { Upregulates IGF2BP1 expression by miR-513, by forming a PCAT6/ miR-513/ IGF2BP1 } \\
\text { positive feedback loop, thus promoting the progression of glioblastoma }\end{array}$ & {$[44]$} \\
\hline Gastrointestinal mesenchymal tumor & High & $\begin{array}{l}\text { Promotes proliferation of gastrointestinal mesenchymal tumor cells through miR- } \\
143-3 p \text { upregulation of PRDX5 }\end{array}$ & {$[47]$} \\
\hline \multirow[t]{2}{*}{ Breast cancer } & High & $\begin{array}{l}\text { Promotes TNBC cell proliferation, migration, invasion, EMT, and angiogenesis, as well } \\
\text { as tumor growth and metastasis via upregulation of VEGFR2 through sponging } \\
\text { miR-4723-5p and recruiting USP14 }\end{array}$ & {$[40]$} \\
\hline & High & $\begin{array}{l}\text { Silencing PCAT6 inhibits the proliferation of triple-negative breast cancer cells and } \\
\text { promoted apoptosis by upregulating the expression of miR-185-5p and down- } \\
\text { regulating the expression of TPD52 }\end{array}$ & {$[38]$} \\
\hline Bile duct cancer & High & $\begin{array}{l}\text { Inhibits cell proliferation and invasion by reducing miR-330-5p expression in bile } \\
\text { duct cancer cells }\end{array}$ & {$[42]$} \\
\hline Pituitary adenoma & High & Promotes pituitary adenoma progression by targeting the miR-139-3p/ BRD4 axis & {$[45]$} \\
\hline
\end{tabular}


for most cancer types remains poor. Therefore, early diagnosis and treatment are important to improve the prognosis in cancer patients. However, the sensitivity and specificity of currently used tumor markers are not satisfactory [40].

LncRNAs are transcribed by RNA polymerase II, and their expression is tissue-specific and highly conserved within mammals. Numerous studies have demonstrated that lncRNAs are involved in a range of biological processes, including X-chromosome silencing, chromatin modification, transcriptional interference and activation, and intranuclear translocation by regulating gene expression in the form of RNA, lncRNAs are involved in almost all human physiological and pathological processes [24]. Recently, the field of lncRNAs has attracted significant attention, and numerous studies have revealed that PCAT6 expression is up-regulated in various cancers, and that PCAT6 has the potential to become a new diagnostic biomarker and therapeutic target.

Kong et al. [24] found that PCAT6 expression was higher in ovarian cancer tissues than in paraneoplastic tissues, and that high PCAT6 expression was strongly associated with poor prognosis in ovarian cancer patients. Shi et al. [45] demonstrated an increased abundance of PCAT6 in TNBC tissues and cells, and found that PCAT6 levels positively correlated with lymph node metastasis and the clinical stage. Shi et al. [25] and Wan et al. [17] both reported that PCAT6 expression was upregulated in lung cancer (in comparison with normal lung tissue), and that PCAT6 expression correlated with the tumor size, lymph node metastasis, and TNM stage. Wang et al. [27] reported that PCAT6 expression was upregulated in pancreatic ductal carcinoma, and that PCAT6 expression correlated with TNM stage, the presence of lymph node metastasis, and OS of patients with pancreatic ductal carcinoma. Wu et al. [23] and Zhu et al. [35] both reported that PCAT6 expression was significantly higher in osteosarcoma tissues (in comparison with normal bone tissues), and that high expression of PCAT6 closely associated with poor prognosis in patients with osteosarcoma. $\mathrm{Xu}$ et al. [33] showed that PCAT6 expression was higher in gastric cancer tissues (compared with normal adjacent tissues), and that PCAT6 expression correlated with TNM stage, lymph node metastasis, and OS in gastric cancer patients. Finally, Zhang et al. [34] and Huang et al. [47] both reported that PCAT6 expression was higher in colon cancer tissues (in comparison with adjacent normal tissues), and that the high expression of PCAT6 closely associated with poor patient prognosis.

The aim of the present study was to elucidate the relationship between PCAT6 and cancer, clinical case characteristics, and prognosis. In our meta-analysis, PCAT6 overexpression significantly correlated with a lower OS and PFS, and PCAT6 overexpression significantly reduced OS and PFS in patients. Validation using TCGA database results confirmed our findings that PCAT6 overexpression significantly correlated with a shorter OS and DFS. Regarding the correlation between PCAT6 overexpression and clinicopathological parameters, our results revealed that men were more likely to show high expression of PCAT6 (one possible explanation is that PCAT6 is associated with sex chromosomes, although this has not been reported). Regarding the correlation between PCAT6 overexpression and tumor size, PCAT6 overexpression and a larger tumor volume significantly correlated (after excluding cervical cancer and osteosarcoma). However, no heterogeneity was observed between the included studies, the results of subgroup analysis revealed that a larger tumor volume and PCAT6 overexpression significantly correlated in lung cancer. As no heterogeneity was observed between the included studies, therefore, it can be concluded that PCAT6 overexpression and a larger tumor volume were associated in lung, colorectal, and bladder cancers. Regarding the correlation between PCAT6 overexpression and TNM stage, a negative correlation was observed between PCAT6 expression and advanced tumor stage (III + IV).

No significant correlation was observed between PCAT6 overexpression and the degree of tumor differentiation. Moreover, subgroup analysis revealed that PCAT6 overexpression did not significantly correlate with the degree of differentiation of lung cancer. These results contrast with the data presented by Shi et al. [25] and Wan et al. [17], who reported completely different results with lung cancer. This difference may be due to the different types of lung cancer included in these two studies. Shi et al. [25] included patients with non-small cell lung cancer, while Wan et al. [17] did not specify the specific lung cancer type of the patients included.

To further investigate PCAT6 expression in various cancers, we used two public databases to determine PCAT6 expression in various cancers. The results revealed that PCAT6 expression was significantly higher in eight cancers, and that high PCAT6 expression strongly associated with poor patient prognosis. These results validated the findings presented in this study.

In the present study, we first explored the role of PCAT6 in tumors and found a significant correlation between PCAT6 overexpression and cancer metastasis. Because of high heterogeneity, we performed subgroup and sensitivity analyses, and these results revealed a significant correlation between PCAT6 overexpression and tumor metastasis in both lung cancer and osteosarcoma. The heterogeneity remained high, therefore, further studies are needed to validate our findings. Several limitations 
of our study should be considered. First, all studies were from the People's Republic of China. Furthermore, only a small number of cases were included, and sample sizes were low for some cancer types. Therefore, the possibility arises that our results apply only to Asian patients. To address this limitation, we subsequently validated our results using public databases, providing support for our conclusions. Second, the HR for OS and PFS as extracted from Kaplan-Meier curves, potentially leading to errors. Third, we offer no standard cut-off value for overexpression and under-expression of PCAT6. Finally, because the included studies were all in English, some studies may have been omitted [48].

\section{Conclusion}

We found that PCAT6 overexpression was significantly correlated with shorter OS and PFS in cancer patients. In addition, a significant correlation was observed between PCAT6 overexpression and individual tumor clinicopathological parameters, including TNM stage, gender, and tumor metastasis. However, PCAT6 overexpression was not associated with patient age and tumor differentiation. In summary, PCAT6 may be useful as a novel tumor predictor, and the critical role of PCAT6 in human cancers should be explored further. To confirm these results and validate their clinical significance, large-scale and multicenter studies will be needed.

\section{Abbreviations}

InCRNA: Long noncoding RNA; PCAT6: Prostate cancer-associated transcript 6; HR: Hazard ratio; OR: Odds ratio; OS: Overall survival; DFS: Disease-free survival; PFS: Progression-free survival; 95\% CI: 95\% Confidence interval; qRT-PCR: Quantitative real-time polymerase chain reaction; NOS: The NewcastleOttawa Quality Assessment Scale; GEPIA: Gene Expression Profiling Interactive Analysis; TCGA: The Cancer Genome Atlas; CHOL: Cholangio carcinoma; LUSC: Lung squamous cell carcinoma; OV: Ovarian serous cystadenocarcinoma; THYM: Thymoma; NGDC: Database Resources of the National Genomics Data Center.

\section{Acknowledgements}

We thank Pro Ke-hu Yang from the Evidence-Based Medicine Center of Lanzhou University for his guidance.

\section{Authors' contributions}

Conception and design of the review: KY, YQ. Acquisition of data: SS, QC, SG. Analysis and interpretation of data: TL, SG, YY, QC. All authors read and approved the final manuscript.

\section{Funding}

This study was supported by the Fundamental Research Funds for the Central Universities (2020jbkyzx001, Izujbky-2020-kb20).

\section{Availability of data and materials}

All data are included in this manuscript.

\section{Declarations}

Ethics approval and consent to participate Not applicable.
Consent for publication

Not applicable.

\section{Competing interests}

The authors declare that they have no competing interests.

\section{Author details}

${ }^{1}$ Gansu Provincial Hospital, 204 Dong gang West Road, Cheng guan District, Lanzhou, China. ${ }^{2}$ Institution of Clinical Research and Evidence-Based Medicine, The Gansu Provincial Hospital, Lanzhou, China. ${ }^{3}$ Evidence-Based Medicine Center, School of Basic Medical Sciences, Lanzhou University, No. 222, Tian shui South Road, Cheng guan District, Lanzhou 730000, China. ${ }^{4}$ Key Laboratory of Evidence-Based Medicine and Knowledge Translation of Gansu Province, Lanzhou, China. ${ }^{5}$ School of Clinical Medicine, Ningxia Medical University, Yinchuan, China. ${ }^{6}$ The First Clinical Medical College of Lanzhou University, Lanzhou, China.

Received: 28 March 2021 Accepted: 6 July 2021

Published online: 12 July 2021

\section{References}

1. Sung H, Ferlay J, Siegel RL, Laversanne M, Soerjomataram I, Jemal A, Bray F. Global cancer statistics 2020: GLOBOCAN estimates of incidence and mortality worldwide for 36 cancers in 185 countries. CA Cancer J Clin. 2021;71:209.

2. Siegel RL, Miller KD, Jemal A. Cancer statistics, 2020. CA Cancer J Clin. 2020;70(1):7-30.

3. Feng RM, Zong YN, Cao SM, Xu RH. Current cancer situation in China: good or bad news from the 2018 Global Cancer Statistics? Cancer communications (London, England). 2019;39(1):22.

4. Zhang F, Chen X, Xi K, Qiu Z, Wang Y, Gui Y, Hou Y, Chen K, Zhang X. Long noncoding RNA HOXD-AS1 in various cancers: a meta-analysis and TCGA data review. Onco Targets Ther. 2018;11:7827-40.

5. Dunn BK, Wagner PD, Anderson D, Greenwald P. Molecular markers for early detection. Semin Oncol. 2010;37(3):224-42.

6. Prensner JR, Chinnaiyan AM. The emergence of IncRNAs in cancer biology. Cancer Discov. 2011;1(5):391-407.

7. Lin C, Yang L. Long Noncoding RNA in Cancer: Wiring Signaling Circuitry. Trends Cell Biol. 2018;28(4):287-301.

8. Wang D, Gao ZM, Han LG, Xu F, Liu K, Shen Y. Long noncoding RNA CASC2 inhibits metastasis and epithelial to mesenchymal transition of lung adenocarcinoma via suppressing SOX4. Eur Rev Med Pharmacol Sci. 2020;24(13):7210.

9. Hu YC, Wang AM, Lu JK, Cen R, Liu LL. Long noncoding RNA HOXD-AS1 regulates proliferation of cervical cancer cells by activating Ras/ERK signaling pathway. Eur Rev Med Pharmacol Sci. 2017;21 (22):5049-55.

10. Renganathan A, Felley-Bosco E. Long noncoding RNAs in cancer and therapeutic potential. Adv Exp Med Biol. 2017;1008:199-222.

11. Lalevée S, Feil R. Long noncoding RNAs in human disease: emerging mechanisms and therapeutic strategies. Epigenomics. 2015;7(6):877-9.

12. Yin Y, Yan P, Lu J, Song G, Zhu Y, Li Z, Zhao Y, Shen B, Huang X, Zhu H, et al. Opposing roles for the IncRNA haunt and its genomic locus in regulating HOXA gene activation during embryonic stem cell differentiation. Cell Stem Cell. 2015;16(5):504-16.

13. Gibb EA, Brown CJ, Lam WL. The functional role of long non-coding RNA in human carcinomas. Mol Cancer. 2011;10:38.

14. Kawaguchi T, Tanigawa A, Naganuma T, Ohkawa Y, Souquere S, Pierron G, Hirose T. SWI/SNF chromatin-remodeling complexes function in noncoding RNA-dependent assembly of nuclear bodies. Proc Natl Acad Sci USA. 2015;112(14):4304-9.

15. Yang G, Lu X, Yuan L. LncRNA: a link between RNA and cancer. Biochem Biophys Acta. 2014;1839(11):1097-109.

16. Zhuang W, Ge X, Yang S, Huang M, Zhuang W, Chen P, Zhang X, Fu J, Qu J, Li B. Upregulation of IncRNA MEG3 promotes osteogenic differentiation of mesenchymal stem cells from multiple myeloma patients by targeting BMP4 transcription. Stem cells (Dayton, Ohio). 2015;33(6):1985-97. 
17. Wan L, Zhang L, Fan K, Cheng ZX, Sun QC, Wang JJ. Knockdown of long noncoding RNA PCAT6 inhibits proliferation and invasion in lung cancer cells. Oncol Res. 2016;24(3):161-70.

18. Hosseini ES, Meryet-Figuiere M, Sabzalipoor H, Kashani HH, Nikzad H, Asemi Z. Dysregulated expression of long noncoding RNAs in gynecologic cancers. Mol Cancer. 2017;16(1):107.

19. He S, Du W, Li M, Yan M, Zheng F. PODXL might be a new prognostic biomarker in various cancers: a meta-analysis and sequential verification with TCGA datasets. BMC Cancer. 2020;20(1):620.

20. Zhong Y, Zhao M, Yu Y, Li Q, Wang F, Wu P, Zhang W, Miao L. Prognostic value and therapeutic potential of the long noncoding RNA TP73-AS1 in cancers: A systematic review and meta-analysis. Sci Rep. 2020;10(1):9053.

21. Wu H, Zou Q, He H, Liang Y, Lei M, Zhou Q, Fan D, Shen L. Long noncoding RNA PCAT6 targets miR-204 to modulate the chemoresistance of colorectal cancer cells to 5-fluorouracil-based treatment through HMGA2 signaling. Cancer Med. 2019;8(5):2484-95.

22. Du Z, Fei T, Verhaak RG, Su Z, Zhang Y, Brown M, Chen Y, Liu XS. Integrative genomic analyses reveal clinically relevant long noncoding RNAs in human cancer. Nat Struct Mol Biol. 2013;20(7):908-13.

23. Wu K, Feng Q, Li L, Xiong Y, Liu S, Liu J, Wu Q. Long-noncoding RNA PCAT6 aggravates osteosarcoma tumourigenesis via the MiR-143-3p/ZEB1 Axis. Onco Targets Ther. 2020;13:8705-14.

24. Kong FR, Lv YH, Yao HM, Zhang HY, Zhou Y, Liu SE. LncRNA PCAT6 promotes occurrence and development of ovarian cancer by inhibiting PTEN. Eur Rev Med Pharmacol Sci. 2019;23(19):8230-8.

25. Shi X, Liu Z, Liu Z, Feng X, Hua F, Hu X, Wang B, Lu K, Nie F. Long noncoding RNA PCAT6 functions as an oncogene by binding to EZH2 and suppressing LATS2 in non-small-cell lung cancer. EBioMedicine. 2018:37:177-87.

26. Lv XJ, Tang Q, Tu YQ, Yan DD, Wei QC. Long noncoding RNA PCAT6 regulates cell growth and metastasis via Wnt/ $\beta$-catenin pathway and is a prognosis marker in cervical cancer. Eur Rev Med Pharmacol Sci. 2019;23(5):1947-56.

27. Wang W, Li X, Guan C, Hu Z, Zhao Y, Li W, Jiang X. LncRNA PCAT6 promotes the proliferation, migration and invasion of pancreatic ductal adenocarcinoma via regulating miR-185-5p/CBX2 axis. Pathol Res Pract. 2020;216(9):153074

28. Yao L, Sun R, Chen YL, Wang Q, Wei D, Wang X, Yang K. The quality of evidence in Chinese meta-analyses needs to be improved. J Clin Epidemiol. 2016;74:73-9

29. Ge L, Tian JH, Li YN, Pan JX, Li G, Wei D, Xing X, Pan B, Chen YL, Song FJ, et al. Association between prospective registration and overall reporting and methodological quality of systematic reviews: a meta-epidemiological study. J Clin Epidemiol. 2018;93:45-55.

30. Xiu-xia L, Ya Z, Yao-long C, Ke-hu Y, Zong-jiu Z. The reporting characteristics and methodological quality of Cochrane reviews about health policy research. Health Policy (Amsterdam, Netherlands). 2015;119(4):503-10.

31. Tang Z, Li C, Kang B, Gao G, Li C, Zhang Z. GEPIA: a web server for cancer and normal gene expression profiling and interactive analyses. Nucleic Acids Res. 2017;45(W1):W98-W102.

32. CNCB-NGDC Members and Partners. Database Resources of the National Genomics Data Center, China National Center for Bioinformation in 2021. Nucleic Acids Res. 2021:49(D1):D18-d28.

33. Xu Y, Sun JY, Jin YF, Yu H. PCAT6 participates in the development of gastric cancer through endogenously competition with microRNA-30. Eur Rev Med Pharmacol Sci. 2018;22(16):5206-13.
34. Zhang D, Du D, Yi S, Li X. LncRNA PCAT6: A potential biomarker for diagnosis and prognosis of bladder cancer. Annals Diagnostic Pathol. 2020:49:151642.

35. Zhu C, Huang L, Xu F, Li P, Li P, Hu F. LncRNA PCAT6 promotes tumor progression in osteosarcoma via activation of TGF- $\beta$ pathway by sponging miR-185-5p. Biochem Biophys Res Commun. 2020;521(2):463-70.

36. Zheng Y, Xu Q, Liu M, Hu H, Xie Y, Zuo Z, Ren J. InCAR: A comprehensive resource for IncRNAs from cancer arrays. Cancer Res. 2019;79(8):2076-83.

37. Cui LH, Xu HR, Yang W, Yu LJ. IncRNA PCAT6 promotes non-small cell lung cancer cell proliferation, migration and invasion through regulating miR330-5P. Onco Targets Ther. 2018;11:7715-24.

38. Guan X, Xu Y, Zheng J. Long non-coding RNA PCAT6 promotes the development of osteosarcoma by increasing MDM2 expression. Oncol Rep. 2020;44(6):2465-74.

39. Xia W, Chen C, Zhang MR, Zhu LN. LncRNA PCAT6 aggravates the progression of bladder cancer cells by targeting miR-513a-5p. Eur Rev Med Pharmacol Sci. 2020;24(19):9908-14

40. Deng C, Hu X, Wu K, Tan J, Yang C. Long non-coding RNA XIST predicting advanced clinical parameters in cancer: A Meta-Analysis and case series study in a single institution. Oncol Lett. 2019;18(3):2192-202.

41. Ma Z, Gu G, Pan W, Chen X. LncRNA PCAT6 accelerates the progression and chemoresistance of cervical cancer through Up-regulating ZEB1 by Sponging miR-543. Onco Targets Ther. 2020;13:1159-70.

42. Xin Y, He X, Zhao W, Zhan M, Li Y, Xiao J, He K, Lu L. LncRNA PCAT6 increased cholangiocarcinoma cell proliferation and invasion via modulating miR-330-5p. Am J Transl Res. 2019;11(9):6185-95.

43. Liu $P$, Zhao $P$, Li B, Xu D, Wang K. LncRNA PCAT6 regulated by $Y Y 1$ accelerates the progression of glioblastoma via miR-513/IGF2BP1. Neurochem Res. 2020;45(12):2894-902.

44. Bai F, Zhang N, Fang W, He X, Zheng Y, Gu D. PCAT6 mediates cellular biological functions in gastrointestinal stromal tumor via upregulation of PRDX5 and activation of Wnt pathway. Mol Carcinog. 2020;59(6):661-9.

45. Shi R, Wu P, Liu M, Chen B, Cong L. Knockdown of IncRNA PCAT6 enhances radiosensitivity in triple-negative breast cancer cells by regulating miR-185-5p/TPD52 Axis. Onco Targets Ther. 2020;13:3025-37.

46. Bray F, Ferlay J, Soerjomataram I, Siegel RL, Torre LA, Jemal A. Global cancer statistics 2018: GLOBOCAN estimates of incidence and mortality worldwide for 36 cancers in 185 countries. CA Cancer J Clin. 2018;68(6):394-424.

47. Huang W, Su G, Huang X, Zou A, Wu J, Yang Y, Zhu Y, Liang S, Li D, Ma F, et al. Long noncoding RNA PCAT6 inhibits colon cancer cell apoptosis by regulating anti-apoptotic protein ARC expression via EZH2. Cell cycle (Georgetown, Tex). 2019;18(1):69-83.

48. Li J, Gao W, Punja S, Ma B, Vohra S, Duan N, Gabler N, Yang K, Kravitz RL. Reporting quality of N-of-1 trials published between 1985 and 2013: a systematic review. J Clin Epidemiol. 2016;76:57-64.

\section{Publisher's Note}

Springer Nature remains neutral with regard to jurisdictional claims in published maps and institutional affiliations.

Ready to submit your research? Choose BMC and benefit from

- fast, convenient online submission

- thorough peer review by experienced researchers in your field

- rapid publication on acceptance

- support for research data, including large and complex data types

- gold Open Access which fosters wider collaboration and increased citations

- maximum visibility for your research: over 100M website views per year

At $\mathrm{BMC}$, research is always in progress.

Learn more biomedcentral.com/submissions 